Int J Epidemiol Health Sci 2021;2(8):e17

doi: http//doi.org/10.51757/IJEHS.2.8.2021.244538

\title{
Effectiveness of family-centered empowerment program on the care needs of families of patients with traumatic head injury
}

\author{
Razieh Akbari ${ }^{1}$, Shayesteh Salehi ${ }^{1, *}$, Nasrollah Alimohammadi ${ }^{2}$
}

${ }^{1}$ Community Health Research Center, Isfahan (Khorasgan) Branch, Islamic Azad University, Isfahan, Iran

2 Nursing and Midwifery Care Research Center, School of Nursing and Midwifery, Isfahan University of Medical Sciences, Isfahan, Iran

*. Corresponding author: Shayesteh Salehi, Community Health Research Center, Isfahan (Khorasgan) Branch, Islamic Azad University, Isfahan, Iran. E-mail: Sh.salehi@khuisf.ac.ir.

Cite this article: Akbari, R.; Salehi, S.; Alimohammadi, N. Effectiveness of family-centered empowerment program on the care needs of families of patients with traumatic head injury. Int J Epidemiol Health Sci 2021;2(8):e17. Doi:10.51757/IJEHS.2.8.2021.244538

\begin{abstract}
Background: Most survivors of traumatic head injury, due to functional disorders, are dependent on their family members. In fact, these families are at the forefront of many challenges and stresses. The aim of the present study was to investigate the effectiveness of a family-centered empowerment program on the care needs of the families of patients with traumatic head injuries discharged from Al-Zahra Hospital in Isfahan in 2019.

Methods: The present study was a clinical trial conducted among 56 family members of patients with traumatic head injury. The samples were randomly allocated to two groups: experiment and control. The experimental group received an empowerment program based on the "family-centered empowerment model" through 3-5 sessions of 45-60 minutes, while the control group received routine education during discharge. Data was collected using a checklist for demographic information as well as the standardized Family Need Questionnaire (FNQ).

Results: Based on the findings of the present study, the level that the care needs have been met regarding health information, emotional support, instrumental support, and professional support was statistically significant higher in the experimental group compared to the control group $(\mathrm{p}<0.001)$. The average care needs related to health information, emotional care, and instrumental support were statistically significant lower in the experimental group compared to the control group ( $\mathrm{p}<0.05)$. While considering community support network, the average care needs were statistically significant lower in the control group compared to the experimental group ( $p<0.05$ ); however, about involvement in care, no statistically significant difference was found between the two groups of experiment and control $(\mathrm{p}>0.05)$.

Conclusion: To meet the care needs of the families of patients with traumatic head injuries discharged from medical centers, implementation of the family-centered empowerment program is effective, and it results in improvement and continuous providing of services at home and meeting families' care needs. Therefore, the application of such programs is recommended for healthcare planners.
\end{abstract}

Keywords: Traumatic head injury, Family caregiver, Family-centered empowerment, Home care

\section{Introduction}

Traumatic head injury is the leading cause of injuryinduced death, and it is addressed as one of the 5 leading causes of death and disability throughout the world, leading to about 5 million deaths per year and 16,000 deaths per day (1). According to a report published by the Centers for Disease Control and 
Prevention, trauma affects more than 10 million people worldwide each year, of which more than 60,000 die (2). Traumatic brain injury confronts communities with problems and challenges in public health and socio-economic conditions (3). In Iran, statistics show that men are more likely than women to suffer from traumatic head injuries (4), and their prevalence is greater in the age group of 25-44 years old (5).

During recent decades, advances in medical sciences and quality improvement in providing acute care have led to increased survival in patients with traumatic head injuries. However, most of the survivors will suffer from some degree of physical and cognitive disabilities, which result in functional and social problems as well as neurological disorders (6). In this regard, several neurological disorders, such as seizures, sleep disorders, and psychiatric diseases, along with non-neurological disorders such as sexual dysfunction, urinary incontinence, gastrointestinal disorders and intestinal problems, and metabolic disorders can be mentioned (7). Undoubtedly, traumatic head injury affects not only the injured person, but also the whole family system. Hence, their families are also considered victims of trauma (8), and they suffer from physical, behavioral, psychological, and social problems.

The most important problems for the families of patients with traumatic head injury could be the changes in roles and tasks (9), stress and sadness (10), tiredness and hopelessness (11), problems in marital relationships (12), anxiety (13), psychological disorders (14), and decreased quality of life (15). Therefore, families should be empowered to manage these problems. Accordingly, one of the most comprehensive and widely used models is the "familycentered empowerment model". This model is designed with the aim of emphasizing the effective role of individuals and other family members regarding the motivational, functional, and psychological dimensions. The feeling of control over the prevailing conditions and the positive changes resulting from the development of family members' performance and ability, as well as their participation, are the basic principles of empowerment (16), since the empowerment of family members will prevent frequent hospitalizations of patients with injuries (17). Therefore, the importance of this issue should be considered by healthcare planners and managers (18). While in Iran, the focus of most studies has been on patients with injuries in recent years (19), and so far, few studies have been conducted on the care needs and the level that the care needs of the families of these patients have been met. The present study aimed to investigate the effectiveness of a family-centered empowerment program on the care needs of the families of patients with traumatic head injuries discharged from Al-Zahra Hospital in Isfahan, Iran in 2019.

\section{Methods}

\section{Setting and sampling}

This study was a randomized controlled clinical trial that was conducted using two groups (experiment and control). The follow-up was performed in three stages (before, immediately after, and one month after the intervention). The required sample size was determined to be 28 in each group.

In the pre-intervention stage, after obtaining the required permission from the Vice Chancellor for Research and Medical Ethics Committee of Islamic Azad University of Khorasgan Branch and presenting it to the Vice Chancellor for Research of Isfahan University, permission to enter Al-Zahra Hospital in Isfahan, Iran, was obtained. Then, permission to conduct the study was obtained by presenting the permission to the manager of the center. The study population consisted of all the family members of patients with traumatic head injuries who were discharged from the hospital from mid-March 2019 to September 2019. The samples were selected through a convenient sampling method first, then they were randomly allocated into two groups of intervention and control using a sample randomization method. The inclusion criteria were willingness to participate in the study, ability to read and write, having a firstdegree relationship with the patient (parents, spouse, sister, brother, child), caring for the patient with a moderate-to-severe traumatic head injury, having not participated in any empowerment program, and living in Isfahan. The exclusion criteria were unwillingness or withdrawal to participate in the study, and the patient's death.

\section{Data collection}

After collecting the demographic information from the patients' files and selecting 56 eligible samples (considering the dropouts), the researchers made a phone call with all participants, introduced themselves, explained the objectives of the study, provided explanations about the importance of the study, emphasized the objectives of the study, and obtained their consent. After holding an introductory session, the questionnaires were distributed among both groups.

Questionnaire 
The questionnaire consisted of two parts. The first part included the patient's personal, clinical, and demographic information (including age, sex, marital status, level of education, cause of traumatic head injury, residence, type of residence, existence of an elevator, clinical status, and type of health insurance), and the caregiver's personal information (including age, sex, marital status, relationship with the patient, occupation, family income, and number of children).

The second part was the standardized Family Needs Questionnaire (FNQ) (20). This questionnaire was first developed in 1989 by Kreutzer and Marwitz. The assessment of needs were done through six subscales of health information, emotional support, instrumental support, professional support, community support network, and involvement in care. The questionnaire consists of 40 items: Health Information (1, 4, 5, 6, 7, $11,12,13,14$, and 18), Emotional Support (29, 30, 34, $36,37,38,39$, and 40), Instrumental Support (22, 23, $24,25,26$, and 27), Professional Support $(15,16,17$, 19,20 , and 21), Community Support Network $(9,10$, $31,32,33$, and 35), and Involvement in Care (2, 3, 8, and 28). The questionnaire is administered in two steps. First, it measures the importance of the needs through a Likert scale from 1-4 (1=not important, $2=$ slightly important, 3 =important, and $4=$ very important); and second, it measures the extent to which each need has been met $(1=$ not met, $2=$ relatively met, and $3=$ met) (20). This questionnaire was translated and validated into the Persian language before (21). The respondents could also choose any item as "Not Applicable" based on their circumstances. At the end of the questionnaire, an open-ended question is provided for family members to express needs that are not included in the questionnaire.

By analyzing the data obtained in the pre-intervention stage, which led to the identification of family members' resources, limitations, needs, and strengths and weaknesses in various fields, the empowerment program was modified and implemented based on the needs and wants of the participants.

After performing the pre-intervention stage, the intervention was performed only for the experimental group, and the control group received only the routine education and program.

\section{The family-centered empowerment program}

In the present study, the family-centered empowerment model was performed in four steps (step by step). The 4 steps included: increasing perceived threat through increasing knowledge, promoting a sense of self-efficacy using problem- solving strategies, enhancing self-esteem through educational participation, and assessment.

The intended outcome of this model was to meet the needs of the families of patients with traumatic head injuries by increasing the perceived threat through group discussion, group problem solving, and practical demonstration. This process was performed during 3-5 sessions to mentally and practically convince the family members that they are able to take an important step towards meeting the needs of their patients and themselves through self-control and adopting appropriate behaviors. For this reason, in order to implement the program to its fullest, an attempt was made to gain the cooperation, the responsibility, and the active participation of the family members of patients with traumatic head injuries in designing the methods and the content of the education, so that, in addition to the knowledge and the skills, the perceived threats and the sense of selfefficacy of the family members of patients increase in order to meet the needs of their patients and themselves, and a positive attitude develops towards caring for the patients. The caregivers are expected to believe that they are capable of helping to implement the empowerment program to meet the needs of themselves, and can effectively assist the family in adopting caring behaviors for the patient. Therefore, regarding the given introduction, which is a summary of the implementation of the family-centered empowerment model, the executive and practical steps of the model are as follows.

Step 1: The aim of perceived severity is to make family members aware of the most important needs of the family, so that by recognizing these needs, one can understand how serious the possible dangers and complications might be and feel threatened about them. At this stage, the participants' knowledge and attitudes towards the nature of traumatic head injury, the definition, the risk factors, the symptoms, the treatment, medical and nursing care, and the prognosis were discussed and reviewed through group discussion with family members for 45 to 60 minutes based on the physical, mental, and psychological conditions of the participants. The number of sessions was different based on the level of the ability and talent of family members to receive and participate effectively in the discussion and exchange of views.

Step 2: The aim of this part is to make one believe that he/she can be effective in accomplishing a task. In other words, self-efficacy refers to one's belief in one's ability to succeed in specific situations or accomplish a task.

To this end, group problem-solving sessions were held with the participation of the family members. In these sessions, attempts were made to seek the help of other 
family members of patients with injuries who have already been successful in meeting the needs of themselves. At this stage, the family members actually encounter their problems, the needs of the family, and the problem-solving process. Family members discussed the needs of the family under the constant and direct supervision of the researchers. During one session of 45-60 minutes, thoughts and experiences were practically exchanged through educational pamphlets, self-care booklets on how to care for the patient, educating how to perform suctioning, educating how to feed through the nasogastric tube, physiotherapy, changing the patient's position in order to prevent pressure injuries, personal hygiene in practice, and choosing the solutions.

Step 3: Since in the family-centered empowerment model, which is influenced by the systemic attitude and the family systems theory, the family plays a powerful role in decision making, increasing their participation and sense of self-efficacy is essential. Therefore, the more informed and responsible this participation is, the better the results can be hoped for. Since patients with traumatic head injuries are partially or completely dependent on family members due to long-term complications, the program should be designed in such a way that the family enters the implementation phase by starting the first stages of learning the empowerment program.

According to the principles of self-efficacy theory, one is empowered through observing success by receiving small rewards such as a pen and a notebook. Hence, the level of self-efficacy has increased step by step, and receiving awards emphasizes the tangible feeling of self-efficacy and the transformation of this feeling from a mental state to an object that is related to the feeling of self-esteem. However, the important point is the continuation of behavior. Therefore, empowering family members as an effective element in meeting the needs of patients with injury and their families is highly important.

Step 4: The aim of the assessment process is to encourage as many family members as possible to be independent and take an active part in meeting the needs of themselves and the patients. Generally speaking, the assessment was considered throughout the implementation of the model and family members were constantly assessed during the intervention.

At the end of the intervention, the specific questionnaires regarding the family-centered empowerment program were completed again in the experimental group, and the collected data was analyzed. Family members were given one month to practice the skills learned and then completed a questionnaire, the results of which indicated whether the family members' needs were met or not.
For the interventional group, the post-intervention stage was performed one month after the intervention; and for the control group, it was performed one month after the pre-intervention stage. To this end, the Family Needs Questionnaire was completed again by the participants. The questionnaire was completed by referring to the patients' houses. The procedure was that the questionnaires were delivered to the patients at home, and the questionnaires were collected the next day. At this stage, no sample loss was observed, and all the questionnaires were collected.

\section{Data analysis}

The collected data was then entered into the SPSS software (version 22), and analyzed. The effectiveness of family-centered empowerment on the care needs of the families of patients with injury in both groups was compared. After completing the sampling, the data was analyzed at two levels using SPSS software (version 22). The first level was related to descriptive statistics (frequency, mean, percentage, and standard deviation) and the second level was related to inferential statistics (Kolmogorov-Smirnov test, Mann-Whitney test, Chi-square test).

\section{Results}

Based on the results of the present study, $48.2 \%$ of the caregivers were female, and the rest $(51.8 \%)$ were male. $84.2 \%$ of the caregivers were married. $73.3 \%$ of the caregivers had a high school diploma, while $26.3 \%$ of them had a university education. Of those, 23 people were self-employed, 17 were government employees, and 17 were unemployed. The mean age was 43.28 years. $43.9 \%$ of the caregivers were the patients' spouses, and $36.8 \%$ were the patients' parents. The cause of trauma and head injuries were reported accidents in most cases $(56.1 \%)$. In terms of clinical status, 43 patients $(75.45 \%)$ were partially dependent, and most of them (98.2\%) had health insurance.

The Kolmogorov-Smirnov tests have been shown in Table 1. According to the results of the Man-Whitney test on the average distribution of patients' family needs, the difference between the average care needs of patients' families regarding health information, emotional care, and instrumental support were lower in the experimental group compared to the control group, and this difference was statistically significant $(\mathrm{p}<0.05)$. Also, the difference between the average care needs of patients' families regarding professional support, community support network, and involvement in care was not statistically significant ( $\mathrm{p}$ $>0.05)$. 
According to Table 2, the difference between the levels that the care needs of patients' families have been met regarding health information ( $p<0.05)$, emotional support, instrumental support, professional support, community support network, and involvement in care was statistically significant between the two groups of intervention and control ( $p$ $<0.001)$. The results also showed that the number of positive responses (met) to the needs of all subscales, mentioned in the experimental group, was much higher than in the control group.

\section{Discussion}

The results of the present study showed that the empowerment program was effective in meeting the needs of the families of patients with traumatic head injuries in most domains, including health information, emotional support, instrumental support, professional support, and community support network. In the family-centered empowerment program, patients' families are empowered based on their needs and they play a powerful role in decision making.

Alhani and colleagues investigated the effect of a family-centered empowerment model on patients with iron deficiency anemia (22). The results of this study revealed that the implementation of this model during three months of follow-up was effective on several indicators, especially the quality-of-life of these patients. The findings of the present study are consistent with the findings of Alhani's study, since in both studies, the nature of the disease was chronic and required a series of steps for the patients as well as their family members to realize the importance of the issue, and in this regard, to take steps to improve their education and skills (22).

The findings of the present study are consistent with the results of the study conducted by Mohagheghi and colleagues (20). In their study, the most important needs were related to health information, and the least were related to involvement in care. There was a statistically significant difference between the importance of caregivers' needs and the caregivers' employment status, patients' age, and patients' clinical status (20).

Kheirollahi and colleagues reported the effect of the intervention of family-centered empowerment on the perceived severity of threat in caregivers of patients with stroke (23). The results revealed that there was no significant difference between the mean scores of perceived severity of threat in the groups before the intervention. However, significant differences were observed in the mean scores of perceived severity of threat in the three dimensions (the social, physical, and spiritual dimensions) in the control group compared to the intervention group, one month after the intervention. As a conclusion, it can be said that family-centered empowerment interventions can reduce care pressures, physical and mental stress, and social isolation in caregivers of patients with stroke (23).

The results of one study conducted with the aim of investigating the effect of a family-centered empowerment model on the knowledge, attitudes, and skills of multiple family caregivers of multiple sclerosis patients by Rabiei and colleagues showed that the two groups were similar in terms of knowledge before the intervention (24). However, after the educational intervention, there was a significant difference between the knowledge of the two groups. Regarding patients' attitudes, the Mann-Whitney test showed similarity between the two groups before the intervention. However, after the educational intervention, $100 \%$ of the patients in the experimental group had positive attitudes towards the subject, while there was no change in the attitudes of the control group. In terms of skills, the Mann-Whitney test showed no significant difference between the two groups before the intervention. However, after the intervention, there was a significant difference $(p<0.001)$. As a conclusion, it can be said that empowering patients with multiple sclerosis leads to improving their knowledge, attitudes, and skills (24). The results of another study conducted by Doser and Norup among the families of patients with severe brain injury in Denmark entitled "Family needs in the chronic phase after severe brain injury in Denmark" showed that the subscale of health information had the highest mean importance rating (Mean $=3.5$, $\mathrm{SD}=0.73$ ), while the subscale of emotional support had the lowest (Mean=3.07, SD=79) (25). In this case, when combining importance and met ratings, it was found that the five most important needs were only met in $41-50 \%$ of the total sample. The employment and co-habitation status of the relatives were significantly affected by the brain injury. A high number of relatives reported family needs not being met in the chronic phase. This requires an interventional approach for families to get these needs fulfilled individually, even after rehabilitation (25).

Murray and colleagues also showed that the subscale of health information had the highest mean importance rating, while the subscale of emotional support had the lowest (26). Krutzer and colleagues conducted a study entitled "A preliminary investigation of the brain injury family intervention" in Virginia in 2009 (27). The results of this study showed that the implementation of a family-based intervention 
program compared to before its implementation significantly increased the needs met regarding the subscales of health information, professional support, emotional support, and involvement in care (27).

Table 1. The care needs of patients' families regarding the subscales of the questionnaire among the two groups of intervention and control

\begin{tabular}{|c|c|c|c|c|c|}
\hline \multirow{2}{*}{ Variable } & \multicolumn{2}{|c|}{ Intervention } & \multicolumn{2}{c|}{ Control } & \multirow{2}{*}{ p-value } \\
\cline { 2 - 5 } & Mean & SD & Mean & SD & \\
\hline Health information & 30.71 & 2.58 & 33.28 & 2.78 & 0.002 \\
\hline Emotional support & 24.36 & 1.66 & 22.79 & 3.19 & 0.040 \\
\hline Instrumental support & 15.93 & 2.57 & 12.17 & 4.74 & 0.006 \\
\hline Professional support & 18.85 & 1.48 & 19.14 & 1.92 & 0.378 \\
\hline Community support network & 16.71 & 2.12 & 15.90 & 2.66 & 0.176 \\
\hline Involvement in care & 11.82 & 1.39 & 11.38 & 1.85 & 0.258 \\
\hline
\end{tabular}

* Man-Whitney test (p-value<0.05), SD: standard deviation

Table 2. The level that the care needs of patients' families has been met among the two groups of intervention and control

\begin{tabular}{|c|c|c|c|c|}
\hline \multicolumn{2}{|l|}{ Items } & Intervention N (\%) & Control N (\%) & P value \\
\hline \multirow[t]{3}{*}{ Health information } & Not met & $2(1.8)$ & $110(98.2)$ & \multirow[t]{3}{*}{0.001} \\
\hline & Relatively met & 79 (32.9) & $161(67.1)$ & \\
\hline & Completely met & $227(82.5)$ & $48(17.5)$ & \\
\hline \multirow[t]{3}{*}{ Emotional support } & Not met & 0 & $59(100)$ & \multirow[t]{3}{*}{$0.001 * *$} \\
\hline & Relatively met & $74(38.5)$ & $118(61.5)$ & \\
\hline & Completely met & $150(73.2)$ & $55(26.8)$ & \\
\hline \multirow[t]{3}{*}{ Instrumental support } & Not met & $1(5.3)$ & $18(94.7)$ & \multirow[t]{3}{*}{$0.001 * *$} \\
\hline & Relatively met & $54(40)$ & $81(60)$ & \\
\hline & Completely met & $113(60.1)$ & 75 (39.9) & \\
\hline \multirow[t]{3}{*}{ Professional support } & Not met & 0 & $54(100)$ & \multirow[t]{3}{*}{$0.001 * *$} \\
\hline & Relatively met & $57(36.1)$ & $101(63.9)$ & \\
\hline & Completely met & $111(85.4)$ & $19(14.6)$ & \\
\hline \multirow[t]{3}{*}{ Community support network } & Not met & 0 & $28(100)$ & \multirow[t]{3}{*}{$0.001 * *$} \\
\hline & Relatively met & $57(41.3)$ & $81(58.7)$ & \\
\hline & Completely met & $111(63.1)$ & $65(36.9)$ & \\
\hline \multirow[t]{3}{*}{ Involvement in care } & Not met & 0 & $38(100)$ & \multirow[t]{3}{*}{$0.001 * *$} \\
\hline & Relatively met & $31(34.8)$ & $58(65.2)$ & \\
\hline & Completely met & $81(80.2)$ & $20 \mathrm{c}(198)$ & \\
\hline
\end{tabular}

$* *$ chi-square test $(\mathrm{p}$-value $<0.001)$ 
In another study conducted by Alah Yari and colleagues, the results showed that the implementation of a family-centered empowerment model was effective in increasing the quality of life of school-age thalassemic children (28).

\section{Conclusions}

This study showed that the mean scores of caregivers' needs in the control group were much higher than in the experimental group, which confirms the great needs of caregivers after discharge. Besides, the average score of meeting the needs in the experimental group was higher, which confirms that the needs of caregivers in the experimental group were met after the implementation of the empowerment program. Therefore, the implementation of the empowerment program to improve the quality of life of these people was effective.

Given the significant relationship between the level of patients' clinical status and the importance of needs, there is no doubt that factors related to traumatic head injuries, such as GCS score at admission, damage to other organs, and length of hospital stay, can affect the importance of needs and their satisfaction. Hence, it is suggested that in future studies, the effect of these variables on the needs of families should be examined. Also, considering the importance of health information in this study, it is suggested that educational programs or booklets related to traumatic head injuries and their complications, rehabilitation, and other issues related to them be prepared and implemented for families and their patients, and the effects of these programs be examined on the importance and satisfaction of the needs.

\section{Ethical Considerations}

This study is the result of a research project approved and financed by the Islamic Azad University of Khorasgan Branch, with the approval number of 23810401972010 and the code of ethics of IR.IAU.YAZD.REC.1398.01. In this study, in order to observe the ethical considerations, after obtaining approval for the subject of the research as well as the required permission, the researchers attended the neurosurgery department and provided sufficient information regarding the confidentiality of information and the voluntary participation in the study to the participants. The study was conducted after obtaining written informed consent.

\section{Acknowledgements}

The authors would like to thank and express their gratitude for the support of the Vice Chancellor for Research of Khorasgan University and the Vice Chancellor for Research of Isfahan University, as well as the officials of Al-Zahra Hospital affiliated with Isfahan University of Medical Sciences, and the family members of patients with traumatic head injuries who participated in the study.

\section{Conflict of Interests}

The authors declare that there is no conflict of interest.

\section{References}

1. Mathers, C.D, Loncar, D. Updated projections of global mortality and burden of disease, 2002-2030: data sources, methods and results. Geneva: World Health Organization. 2005:1-12. Available from: https://www.who.int/healthinfo/statistics/bod_project ions2030 paper.pdf.

2. Centers for Disease Control and Prevention. National Center for Health Statistics: Mortality Data on CDC WONDER. Available at: https://wonder.cdc.gov/mcd.html.

3. Peeters, W., Van Den Brande, R., Polinder, S., Brazinova, A., Steyerberg, E.W., Lingsma, H.F., Maas, A.I. Epidemiology of traumatic brain injury in Europe. Acta Neurochir (Wien) 2015;157(10):168396.

4. Ebrahimi Fakhar, H, Zand, S. Epidemiology of brain injuries of patients hospitalized in Arak. Iran $\mathbf{J}$ Epidemiol 2011; 6(4): 61-65.

5. Rahimi Movaghar, V., Saadat, S., Rasouli, M.R., Ghahramani, M., Eghbali, A. The incidence of traumatic brain injury in Tehran, Iran: a populationbased study. Am Surg 2011;77(6):112-4.

6. Mcallister, T.W. Neurobehavioral sequelae of traumatic brain injury: evaluation and management. World Psychiatry 2008; 7(1): 3-10.

7. Hora, E.C., De Sousa, R.M.C., De Oliveira Ribeiro, M.D.C., Da Silva Nunes, M., Araújo, R.D.C.V., Dos Santos, A.C.F.S., Cartaxo, C.K.A., Santana, L.V. Traumatic brain injury: Consequences and Family needs. Brain Injury-Functional Aspects, Rehabilitation And Prevention 2012:161-174.

8. Cole, W.R., Paulos, S.K, Cole, C.A., Tankard, C. A review of family intervention guidelines for pediatric acquired brain injuries. Dev Disabil Res Rev 2009;15(2):159-66.

9. Cataldo, F., Kielmann, K., Kielmann, T., Mburu, G., Musheke, M. 'Deep down in their heart, they wish they could be given some incentives': a qualitative study on the changing roles and relations of care among home- 
based caregivers in Zambia. BMC Health Serv Res 2015;15:36.

10. Malec, J.F., Van Houtven, C.H., Tanielian, T., Atizado, A., Dorn, M.C. Impact of TBI on caregivers of veterans with TBI: Burden and interventions. Brain Inj 2017;31(9):1235-1245.

11. Carlozzi, N.E., Kratz, A.L., Sander, A.M., Chiaravalloti, N.D., Brickell, T.A., Lange, R.T., Hahn, E.A., Austin, A., Miner, J.A., Tulsky, D.S. Healthrelated quality of life in caregivers of individuals with traumatic brain injury: development of a conceptual model. Arch Phys Med Rehabil 2015;96(1):105-13.

12. Tyerman, A., Booth, J. Family interventions after traumatic brain injury: A service example. NeuroRehabilitation 2001;16(1):59-66.

13.Watanabe, Y., Shiel, A., Asami, T., Taki, K., Tabuchi, K. An evaluation of neurobehavioural problems as perceived by family members and levels of family stress 1-3 years following traumatic brain injury in Japan. Clin Rehabil 2000;14: 172-177.

14.Qadeer, A., Khalid, U., Amin, M., Murtaza, S., Khaliq, M.F, Shoaib, M. Caregiver's burden of the patients with traumatic brain injury. Cureus 2017;9(8):e1590.

15.Groswasser, Z., Peled, I., Ross, S.H., Truelle, J.L., Von Steinbüchel, N. Validation of the QOLIBRIQuality of Life after Brain Injury questionnaire in patients after TBI in Israel. Brain inj 2018;32(7): 879888.

16. Khezri, R., Ravanipour, M., Motamed, N., Vahedparast, H. Effect of self-management empowering model on the quality of life in the elderly patients with hypertension. Iran J Ageing 2016;10(4): 68-79.

17. Ghaderi, H., Shafiee, H., Amery, H., Vafaeinasab. M.R. The cost-effectiveness analysis of hospital compared to at homecare for CVA patients. J Healthcare Manag 2013;4 (3-4):7-15.

18. Anke, A., Manskow, U.S., Friborg, O., Røe, C., Arntzen, C. The family experiences of in-hospital care questionnaire in severe traumatic brain injury (FECQTBI): a validation study. BMC Health Serv Res 2016;16(1):675.

19. Hora, E.C., Sousa, R.M.C. Cross-cultural adaptation of the instrument" Family Needs Questionnaire". Rev Latino-Am Enfermagem 2009;17(4):541-547.

20. Marwitz, J. The Family Needs Questionnaire. The Center for Outcome Measurement in Brain Injury. Availkable from: http://www.tbims.org/combi/fnq. Accessed at June 11, 2021.

21. Mohagheghi Niadekan, S.H., Yegane Rastekenari, M., Paryad, E., Atrkar-e Roshan, Z. Needs of Caregivers of Patients with Head Trauma after
Discharge And Level of its Fulfillment. J Holist Nurs Midwifery 2016;26 (2):79-89.

22. Alhani, F., Niknami, S., Kimiagar, S., Kazemnejad, A., Hidarnia, A. Designing familycentered empowerment model and measuting the effect on the prevention of iron deficinecy in adolesecnt girls. Pajohandeh 2003;8(4):283-289.

23.Kheirollahi, N., Khatiban, M., Oshvandi, K., Alhani, F., Feradmal, J. The effect of family-centered empowerment intervention on perceived severity of threat in caregivers of patients with stroke: a semi experimental study. Avicenna J Nurs Midwifery Care 2014;22 (3):73-82.

24. Rabiei, L., Sharifirad, G.H., Masoodi, R., Mostafavi, F., Esmaeili, S.A., Daniali, S.H. Knowledge, attitude and skill of multiple sclerosis patients: The effect of family-centered empowerment model. Health System Res 2012;8(2):247-259.

25. Doser, K., Norup, A. Family needs in the chronic phase after severe brain injury in Denmark. Brain Inj 2014;28: 1230-7.

26. Murray, H.M., Maslany, G.W., Jeffery, B. Assessment of family needs following acquired brain injury in Saskatchewan. Brain Inj 2006;20(6):575-85.

27.Kreutzer, J.S., Rapport, L.J., Marwitz, J.H., Harrison-Felix, C., Hart, T., Glenn, M., Hammond, F. Caregivers' Well-being after traumatic brain injury: A multicenter prospective investigation. Arch Phys Med Rehabil 2009;90(6):938-946.

28. Allahyari, A., Alhany, F., Kazemnejad, A., Izadyar, M. The effect of family-centered empowerment model on the quality of life of schoolage B-thalassemic children. Iran $J$ Pediatr 2006;16(4):454-461. 